\title{
Fernand Hallyn, Descartes. Dissimulation et ironie
}

\section{Grazia Lana}

\section{OpenEdition}

\section{Journals}

\section{Edizione digitale}

URL: https://journals.openedition.org/studifrancesi/26226

DOI: 10.4000/studifrancesi.26226

ISSN: 2427-5856

\section{Editore}

Rosenberg \& Sellier

\section{Edizione cartacea}

Data di pubblicazione: 1 avril 2007

Paginazione: 173

ISSN: 0039-2944

\section{Notizia bibliografica digitale}

Grazia Lana, «Fernand Hallyn, Descartes. Dissimulation et ironie», Studi Francesi [Online], 151 (LI | I) | 2007, online dal 30 novembre 2015, consultato il 23 novembre 2021. URL: http://

journals.openedition.org/studifrancesi/26226 ; DOI: https://doi.org/10.4000/studifrancesi.26226

\section{Questo documento è stato generato automaticamente il 23 novembre 2021.}

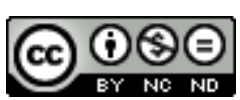

Studi Francesi è distribuita con Licenza Creative Commons Attribuzione - Non commerciale - Non opere derivate 4.0 Internazionale. 


\title{
Fernand Hallyn, Descartes. Dissimulation et ironie
}

\author{
Grazia Lana
}

\section{NOTIZIA}

FERNAND HALLYN, Descartes. Dissimulation et ironie, Genève, Droz, 2006, pp. 215.

1 In questo importante saggio Fernand Hallyn riesce, in modo chiaro e coinvolgente, a mettere in grado il lettore di penetrare nella complessità della scrittura di Descartes e, facendo luce sulla sua pratica della dissimulazione - sintetizzabile nel celebre larvatus prodeo - di capire il metodo che egli utilizza per diffondere ed imporre il suo pensiero. «C'est la manière dont le langage donne accès au sens à travers une rhétorique, avec ses motivations dans la mission que Descartes s'assigne et dans le contexte où il le poursuit, qui constituera l'objet de cette enquête» (p. 8).

2 Il volume consta di una Introduzione sulla pratica della dissimulazione in generale, arte difficile, benché necessaria, all'epoca di Descartes, non solo per l'uomo di corte ma anche nel discorso filosofico e scientifico e adottata soprattutto dai libertini. Sono distinti, seguendo Bacone, tre gradi ne «l'art de voiler son moi»: la riserva, che corrisponde alla discrezione, al segreto, al silenzio; la dissimulazione propriamente detta, che tende a non dire ciò che è o ciò che si pensa; infine la simulazione, che consiste ad affermare positivamente ciò che non è o ciò che non si pensa. La dissimulazione e la simulazione sono per altro strettamente legate all'ironia verbale, come è dimostrato anche dalla retorica latina che utilizza a volte il termine "dissimulazione" per tradurre il greco eironeia.

3 Lo studio si divide in due parti: la prima («Parcours: les vicissitudes de l'art de la prudence») comprende due capitoli e propone una breve sintesi sul ricorso a diverse forme di prudenza e di dissimulazione nell'itinerario di Descartes; un posto privilegiato è riconosciuto al Monde, primo trattato di fisica, mai pubblicato, probabilmente in seguito al processo subito da Galileo, di cui in seguito l'autore non smetterà di voler 
diffondere le idee che si allontanavano dall'ortodossia, sia per la cosmogonia che per la cosmologia, ma che potevano assicurare all'uomo un avvenire migliore.

4 I quattro capitoli che formano la seconda parte («Analyses») sono consacrati a problematiche particolari all'interno dell'itinerario di Descartes, procedono per genere di discorso - fisico, metafisico e polemico - e propongono tre "metafigure" che sono anche forme di ironia verbale: l'enfasi, l'equivoco e l'ipocrisia che possono essere associate ai tre gradi di Bacone e che rispondono ai tre tipi di dissimulazione già enunciati da Ermogene: l'allusione, l'obliquo ed il contrario. Dall'enfasi del Monde si passa perciò agli equivoci nelle Méditations ed all'ipocrisia riscontrabile nella polemica che oppone a Descartes Henricus Regius.

5 In fisica come in metafisica, il ricorso a queste diverse forme di prudenza doveva costituire una specie di barricata contro lo scetticismo e contro i sospetti di eterodossia; ma volendo, soprattutto, far valere la sua filosofia come la sola valida e degna di imporsi a tutti, Descartes, che ha saputo mescolare abilmente franchezza e dissimulazione, non ha come unico obiettivo quello di proteggere la sua sicurezza, ma anche quello di affermare la sua superiorità e di risvegliare nel lettore il desiderio di una rivelazione finalmente completa della nuova filosofia.

6 Il volume è concluso da una ricca bibliografia. 